\title{
Rainwater Harvesting System: An Approach for Optimum Tank Size Design and Assessment of Efficiency
}

\author{
Sadia Tamanna Khan, Ashef Ainan Baksh, Md Tarikul Islam Papon, and Muhammad Ashraf Ali
}

\begin{abstract}
Considering the increasing salinity intrusion in coastal areas, pollution of surface water bodies, groundwater contamination by arsenic and manganese, and groundwater depletion due to excessive withdrawal, rain water harvesting (RWH) has become a potential source of water supply in coastal and arsenic affected area in Bangladesh. A user-friendly software using a simulation model has been developed and employed to estimate the optimum rainwater storage tank size, which is the most costly component of a RWH system. The procedure developed constitutes an effective tool for estimation of the most satisfactory storage capacity for any combination of location, catchment area and material, and water demand. The software also estimates reliability of the corresponding water supply system. The runoff coefficient for various types of materials and the rooftop area for the concerned household are considered as variables. The rainfall data for a 24 -year period for different areas of Bangladesh was collected from Bangladesh Meteorological Department (BMD) and used in the model. Yield After Spillage (YAS) concept was used to develop the program, which provides estimation on the actual rainwater availability and storage conditions. Volumetric reliability index was employed to find the optimum size of the rooftop rain water harvesting (RWHS) tank size, and the corresponding time reliability was determined. Volumetric reliability has been determined considering water demand for drinking and cooking purposes only. The software will provide optimum tank size in terms of size and efficiency along with the approximate functional period for any location in Bangladesh for any particular family size and roof catchment. The software was employed to assess RWHS in a coastal area (Khulna), in an arsenic affected area (Comilla) and a low-precipitation area (Rajshahi). The software would be very useful in determining optimum tank size of RWHS and estimating operational period of such systems for any area of Bangladesh.
\end{abstract}

Index Terms-Rain water harvesting (RWH), storage capacity, time reliability, volume reliability.

\section{INTRODUCTION}

Bangladesh has achieved commendable success in expanding access to safe drinking water, and has met the MDG target; however, nationally about 13 percent population still use "unimproved" water sources [1], which include among others surface water sources and rainwater harvesting. Elevated levels of arsenic in groundwater in south, south-western and north-eastern parts of the country [2]-[4] has forced people to choose surface water sources or rainwater harvesting system (RWHS) for drinking purpose. On a national scale, 25.5 percent of water sources have

Manuscript received April 30, 2016; revised July 1, 2016.

The authors are with Bangladesh University of Engineering and Technology (BUET), Dhaka 1000, Bangladesh (e-mail: ashraf@ce.buet.ac.bd, mashrafali88@gmail.com). arsenic concentration exceeding the $\mathrm{WHO}$ guideline value of $10 \mathrm{ppb}$, and 12.5 percent have arsenic exceeding national standard of $50 \mathrm{ppb}$ [5]. People in the salinity-affected southern coastal areas of Bangladesh are dependent on RWHS (during wet season) and pond water for potable water supply [6]. Pond sand filters (PSFs) and RWHS together account for $6.7 \%, 5.9 \%$, and $9.1 \%$ of water supply points, respectively in Khulna, Satkhira and Bagerhat districts, which are the major coastal districts suffering from both high salinity and arsenic contamination [7]. After the devastating Cyclone Sidr in 2007 and Cyclone Aila in 2009, many sweet water ponds in the coastal areas and offshore islands have become contaminated with saline water, and still remain unusable for potable use. Besides, pollution of pond water from onsite sanitation facilities, discharge of domestic wastewater/sullage and unintended use of ponds (e.g., washing, bathing) make them less attractive and unsafe as a source of potable water supply. As a result, people in the coastal areas have become more dependent on rainwater harvesting.

Being a tropical country which receives heavy rainfall due to north-easterly winds during the rainy season, rainwater can be a potential source of alternative water supply in many areas of Bangladesh. Institute of Water Modeling (IWM) recently estimated that with the current amount of rainfall, around 149,160 million liters of water can be harvested during monsoon [8]. The average yearly rainfall in Bangladesh varies from 2200 to $2800 \mathrm{~mm}, 75 \%$ of which occurs between June and October. The high rainfall intensity provides good opportunity for rainwater harvesting [9].

While rainwater harvesting (RWH) is being practiced in many regions of Bangladesh, its design has received limited attention from professionals. Among the components of RWHS, the storage tank is the most expensive and critical component; it also dictates the volume and time reliability of a RWHS. Therefore, proper sizing of storage tank affects user acceptance and performance of a RWHS. The typical catchment (i.e., roof) area and rainfall intensity, the two most important parameters for estimation of optimum storage size for RWHS, vary widely within the country. Hence, it is important to develop tools for quick and reliable estimation of optimum size of storage tank for RWHS considering catchment area, rainfall intensity, user number and other factors. At the same time it is also important to assess reliability of RWHSs to provide safe water under a given scenario. This paper presents a model and its application for estimation of RWH tank size for any area and for any combination of roof area, material and user number. The model also determines the volumetric and time reliability of rainwater harvesting system, including the time period during which the system will remain operational. 


\section{Methodology}

The present study has been carried out to develop a tool to determine the optimum tank size for rooftop catchment rainwater harvesting system and to analyze the reliability of the tank to meet the water demand for any location.

\section{A. Storage Tank Design Approach}

The hydrological performance of a rainwater tank is related to the size and characteristics of the contributing catchment, level of rainfall, and demand of the system. A number of methods are available for determining the size of the storage tank on rainwater harvesting system. These can be broadly categorized as: a) Demand side approach; b) Graphical (mass curve, Ac-Vc method, etc.) approach; and c) Computer based simulation or behavioral models.

The demand side approach does not account for the possibility that the rainfall patterns may not provide enough rain to fill the tank immediately before the dry period. Due to the assumptions this approach entails, the result can lead to a less reliable water supply than expected. Graphical methods are used for rapid assessment and are considered as preliminary design techniques. The main limitation is that it is not possible to compute storage size for a given reliability of supply. By using this method reliability based storage tank cannot be designed. Moreover, it is not possible to investigate the performance of the system and it is not flexible.

The most accurate method for determining the optimal tank size is to simulate the behavior of the tank by using a computer model. The fluctuations of rainfall are incorporated in this system. This method is chosen to estimate the optimum tank size since it does not overestimate the tank size as in demand side approach and graphical method.

Sizing a rainwater tank by using computer based simulation can become rather complicated as the required size is dependent on a number of factors. The optimal tank size depends on the collection system, the area of the roof from which water will be collected, the volume of water that the tank will be required to supply, whether the demand will be constant or variable, the required reliability of the water supply from the tank, the depth of precipitation which can be expected and the rainfall pattern of the area where the tank will be situated [10].

The conservation of volume approach simply ensures the volume of water in the tank at the end of a given time-step must be equal to the volume of water in the tank at the beginning of the time-step (end of the previous time-step) plus the amount of water that has entered the tank during the given time-step minus the water which has left the tank during the time-step, and is given by the following equation:

$$
0<V_{t}<S
$$

where, $V_{t}$ is the volume of rainwater in the tank at the end of the time interval $t ; Q_{t}$ is the volume of rainwater that enters the tank during time interval $t$; and $S$ is the maximum storage capacity.

Inflow and outflow from a tank is a continuous process in time. By approximating this process with discrete time intervals, the inflow and outflow over the time interval has to be reduced to a point inflow and point outflow. Two different approaches can be used to overcome the problem: a) Yield
After Spillage (YAS), and b) Yield Before Spillage (YBS). For yield-after-spill (YAS) approach, the rainwater is added to the tank and the spillage is immediately removed by limiting the tank volume [11]. At the end of the time-step, the water demand from the tank is subtracted from a volume which can never exceed the maximum storage volume. In reality the water could be removed and rainwater added to the tank simultaneously. For this approach the following equations can be used to determine the yield from the tank and the volume of water in the tank [12].

$$
\begin{gathered}
Y_{t}=\min \left(D_{t}, V_{t-1}\right) \\
V_{t}=\min \left(V_{t-1}+Q_{t}-Y_{t}, S-Y_{t}\right)
\end{gathered}
$$

where, $Y_{t}$ is the yield from the tank during the time interval $t$; $V_{t}$ is the volume of rainwater in the tank at the end of time interval $t ; Q_{t}$ is the volume of rainwater that enters the tank during time interval $t ; D_{t}$ is the demand (volume of water that is removed from the tank) during time interval $t$; and $S$ is the maximum storage capacity.

The yield-before-spill (YBS) approach effectively does not allow the tank to spill during the time step. It collects all the inflow, and satisfies the full demand. If any surplus remains at the end of the time step, this surplus is spilled. This has the opposite effect on the tank capacity and thus overestimates the water which can be supplied by the tank. [13].This approach is described by the following equations [14].

$$
\begin{gathered}
Y_{t}=\min \left(D_{t}, V_{t-1}+Q_{t}-Y_{t}\right) \\
V_{t}=\min \left(V_{t-1}+Q_{t}-Y_{t}, S\right)
\end{gathered}
$$

where the symbols are as described above.

The reliability of a rainwater storage system can be expressed using either time or volumetric basis. Volumetric reliability is the ratio of the total volume of water supplied and the total water demand [15].

$$
R_{v}=\frac{\left(V_{t-1}\right)+\sum_{t=1}^{T} Q_{t}}{\sum_{t=1}^{T} D_{t}}
$$

Time reliability is the fraction of time in which demand is fully met [16]. It can be expressed as:

$$
R_{t}=1-\frac{d_{f}}{n}
$$

where, $R_{t}$ is the time reliability, $d_{f}$ is the number of failure days, $n$ is the total number of days.

\section{B. Development of the Software for Determination of Optimum Tank Size of RWH System}

To simulate the performance of a RWHS, a water-balance simulation model on daily time step was built using JAVA. This model accounted for various factors for a RWHS, such as tank size, daily rainfall, daily water demand, coefficient of the catchment, and catchment area. A behavioral model (yield-after-spillage type) was adopted to simulate the long-term water balance of a RWHS. The YAS approach has been recommended for design purpose [17] as it gives a conservative estimate of system performance.

For the model, precipitation data from all 34 
meteorological station of Bangladesh Meteorological Department (BMD) were collected for a period of 24 years; the data were analyzed and processed for using in the model using pivot table. In the model, the rainfall was regarded as inflow and the release and possible spillage as outflow. The basic logic was simply to take the volume that will remain after the extraction of the yield and addition of the runoff into tank (inflow) if it is larger than the volume after subtracting the yield from the initial assumed storage volume. The optimal size of the storage tank will be the minimum volume for which maximum demand ratio can be found.

The program was also arranged in a process to give a graphical representation of the volumetric reliability versus optimum tank volume and time reliability versus optimum tank volume. As such the user will have a choice on what level of service they demand depending on their ability and their preference on time or cost.

\section{Application of the Software}

Three areas have been chosen for estimation of optimum tank size for different operational conditions, and estimation of reliability. These areas are Khulna, Comilla and Rajshahi. Khulna is a salinity-affected coastal area, Comilla is an area affected by arsenic contamination of groundwater, and Rajshahi is a dry area, which suffers from water scarcity especially during the dry season. The software is developed to give the optimum tank size through counting the rainfall data over the years. YAS method is used to calculate the volume. After the basic inputs (runoff co-efficient, catchment area and the rainfall intensity from rainfall data), optimum tank size is viewed as an output. The variation of RWHS tank reliability has been estimated by taking a catchment area of $100 \mathrm{sft}$. Typical catchment area for rural areas in the coastal regions varies from 37-115 sqm (400-1200 sft) [6], and it has been assumed that at least $25 \%$ of the rooftop area $(\sim 100 \mathrm{sft})$ will be available for use as rainwater catchment.

The variation of tank reliability was assessed by varying the catchment area and keeping the demand constant. As the RWHS tank is basically designed to supply water to a family only for drinking and cooking purpose, a demand of 5 liter per capita per day was assumed, considering local conditions. Considering a family/ user size of 10 persons, a daily water demand was set at $0.05 \mathrm{~m}^{3} /$ day.

Different types of materials are used as roofing materials in Bangladesh, including thatched roof, and corrugated sheets. Considering a runoff coefficient of 0.50 for thatched roof, and 0.9 for corrugated sheet [18], a runoff coefficient of 0.7 was used for reliability assessment.

\section{RESULTS AND DISCUSSIONS}

The efficiency of a rain water harvesting tank can be determined by assessing its reliability. Volumetric reliability gives the measure of how much the tank will be reliable to meet the demand with the available supply to support a family. Time reliability is a measure of the efficiency of the tank with respect to time i.e., how long it will be able to meet the demand of a family.

\section{A. Effect of Regional Variation}

Fig. 1, 2 and 3 show the distribution of rainfall for the three locations for which the software was applied. Among these, Rajshahi is a region with low precipitation.

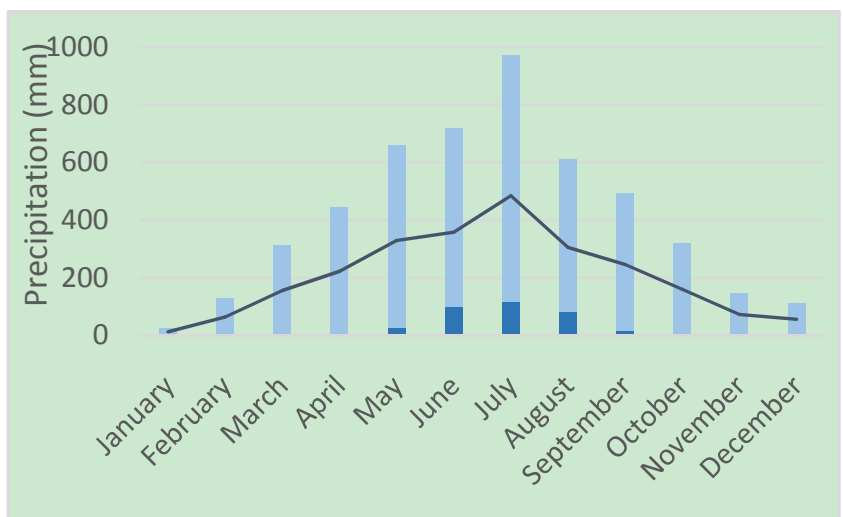

Fig. 1. Monthly distribution of rainfall in application area Comilla.

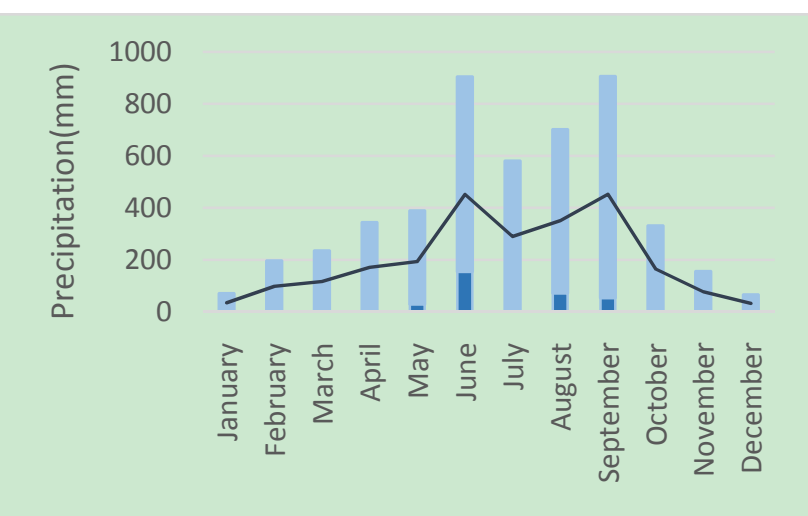

Fig. 2. Monthly distribution of rainfall in application area Khulna.

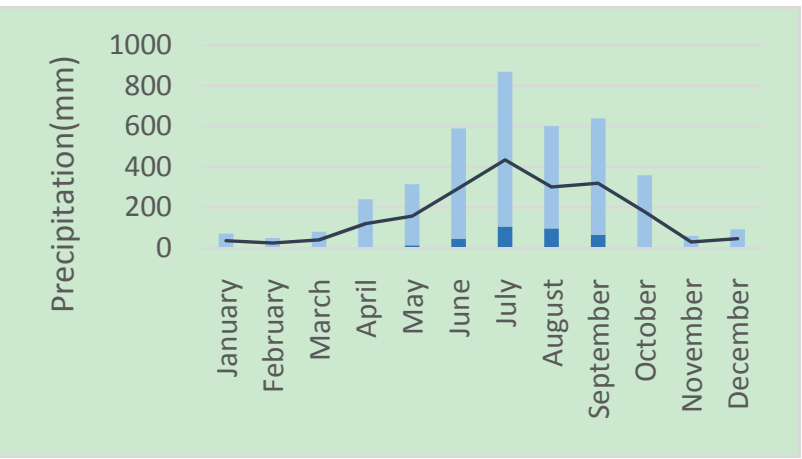

Fig. 3. Monthly distribution of rainfall in application area.

TABLE I: TANK SIZE FOR DIFFERENT RELIABILITY AND CATCHMENT (FOR A 10 PERSON FAMILY)

\begin{tabular}{|c|c|c|c|c|c|}
\hline & \multicolumn{5}{|c|}{ ren } \\
\hline \multirow[b]{2}{*}{ Catchment Area } & \multirow{2}{*}{\multicolumn{2}{|c|}{ Reliability (\%) }} & \multicolumn{3}{|c|}{ Tank Size (cubic meter) } \\
\hline & & & Khulna & Rajshahi & Comilla \\
\hline \multirow{6}{*}{$\begin{array}{c}9.29 \mathrm{sqm} \\
(100 \mathrm{sft})\end{array}$} & \multirow{3}{*}{$\mathrm{R}_{\mathrm{v}}$} & 50 & 1.00 & 1.40 & 1.00 \\
\hline & & 80 & - & - & - \\
\hline & & 90 & - & - & - \\
\hline & \multirow{3}{*}{$\mathrm{R}_{\mathrm{t}}$} & 50 & 1.00 & 1.30 & 1.00 \\
\hline & & 80 & - & - & - \\
\hline & & 90 & - & - & - \\
\hline \multirow{6}{*}{$\begin{array}{c}18.58 \mathrm{sqm} \\
(200 \mathrm{sft})\end{array}$} & \multirow{3}{*}{$\mathrm{R}_{\mathrm{v}}$} & 50 & 1.00 & 1.00 & 1.00 \\
\hline & & 80 & 3.40 & 4.90 & 4.10 \\
\hline & & 90 & 5.50 & 7.20 & 6.30 \\
\hline & \multirow{3}{*}{$\mathrm{R}_{\mathrm{t}}$} & 50 & 1.00 & 1.00 & 1.00 \\
\hline & & 80 & 4.00 & 5.20 & 4.50 \\
\hline & & 90 & 6.00 & 7.60 & 6.70 \\
\hline
\end{tabular}


Table I shows the optimum tank size for the three locations for different reliability figures (varying from 50 to 90 percent) for two different sizes of catchment. It shows location (i.e., regional precipitation pattern) has a significant effect on tank size. For a particular reliability and catchment area, a higher volume tank is required in Rajshahi, compared to Khulna and Comilla. Fig. 4 and 5 show volumetric reliability and time reliability, respectively, for different tank sizes for the three locations/areas for which the software was run. The volumetric reliability and time reliability show that optimum tank size is a strong function of rainfall pattern in a particular area. For the assumed catchment size and user number, a low precipitation region like Rajshahi will not be able to supply water for more than 7 months (i.e., $60 \%$ time reliability).

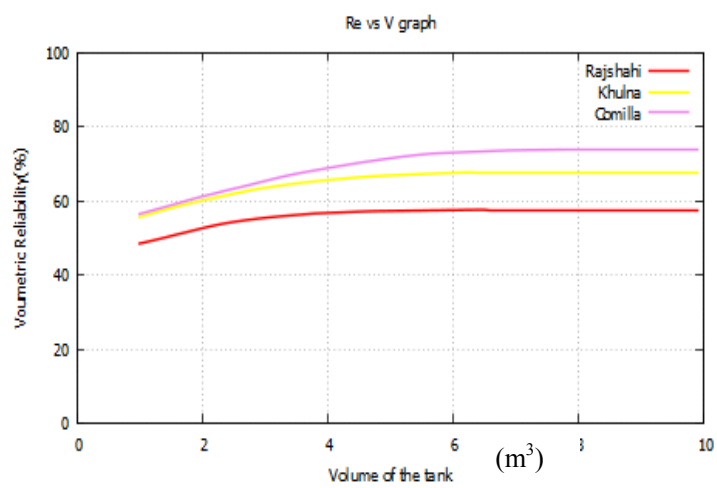

Fig. 4. Effect of location on Volumetric reliability.

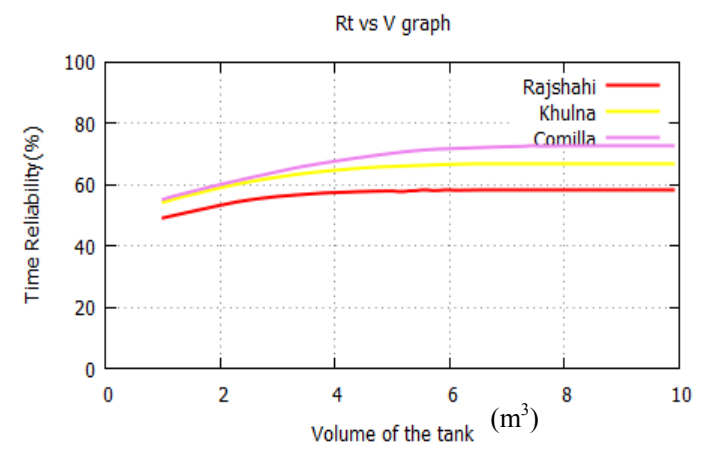

Fig. 5. Effect of location on time reliability.

\section{B. Effect of Water Demand}

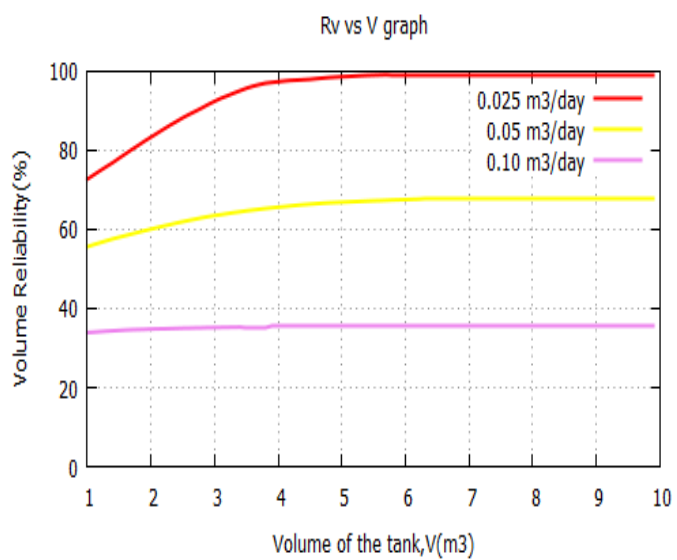

Fig. 6. Volumetric reliability of Comilla for a constant catchment area of $9.29 \mathrm{sqm}(100 \mathrm{sft})$.

The water collected by rainwater harvesting system is usually assumed to be used only for drinking and cooking purposes. Variation in family/user size will induce a change in the water demand. Therefore, with the inflow being constant, a particular water tank will be able to serve a family over shorter period of the year as family size increases. Fig. 6 , 7 and 8 show volume reliability and Fig. 9, 10 and 11 show time reliability for different water demand (i.e., different family size) and different tank sizes in Comilla, Khulna and Rajshahi. For a particular tank size, the reliability decreases as water use (or family size) increases.

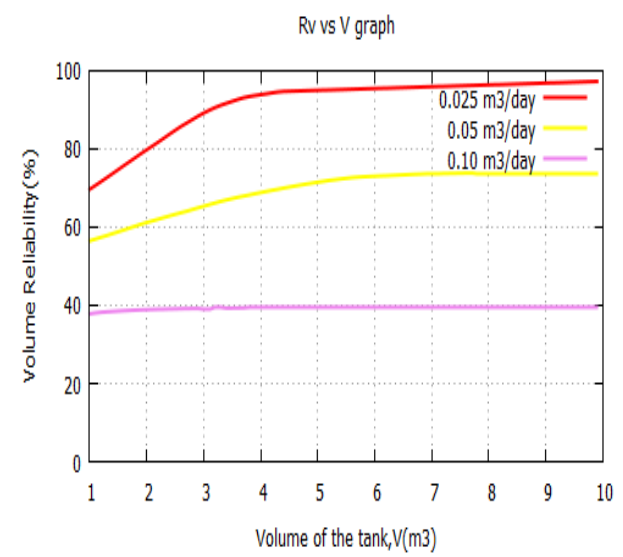

Fig. 7. Volumetric reliability of Khulna for a constant catchment area of 9.29 $\operatorname{sqm}(100 \mathrm{sft})$.

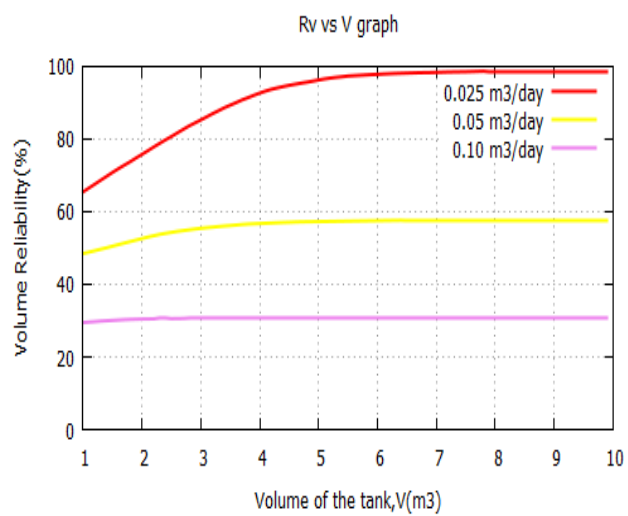

Fig. 8. Volumetric reliability of Rajshahi for a constant catchment area of $9.29 \mathrm{sqm}(100 \mathrm{sft})$

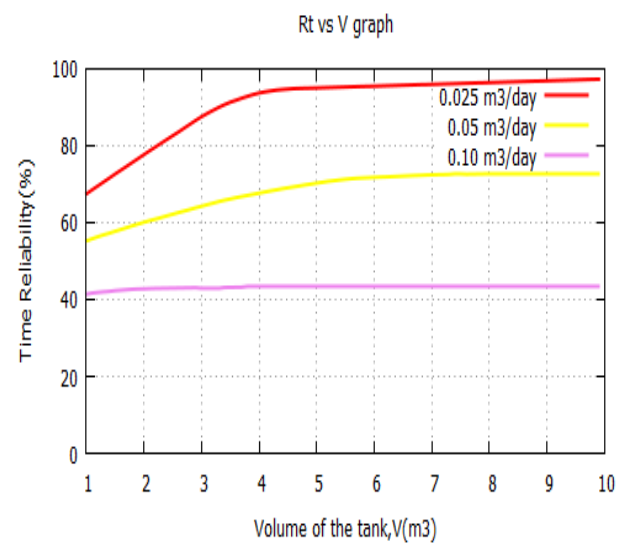

Fig. 9. Time reliability of Comilla for a constant catchment area of $9.29 \mathrm{sqm}$ (100sft).

\section{Effect of Catchment Area}

With the increase in catchment area, the inflow increases; as a result the tank becomes more reliable in terms of volume. The catchment area is basically the rooftop of the house which varies widely. For a small roof area rainwater inflow will be less, and therefore volumetric reliability would also 
be low. Fig.12, 13 and 14 show volume reliability and Fig. 15, 16 and 17 show time reliability for three different catchment areas and different tank sizes in Comilla, Khulna and Rajshahi. For a particular tank size, the reliability increases as catchment area increases.

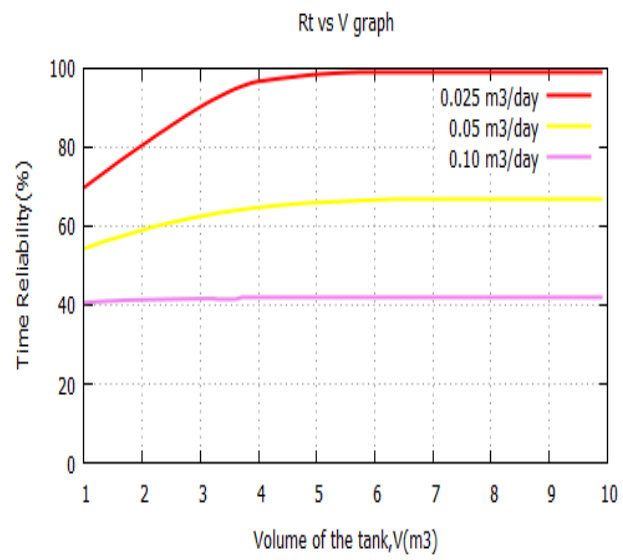

Fig. 10. Time reliability of Khulna for a constant catchment area of $9.29 \mathrm{sqm}$ (100sft).

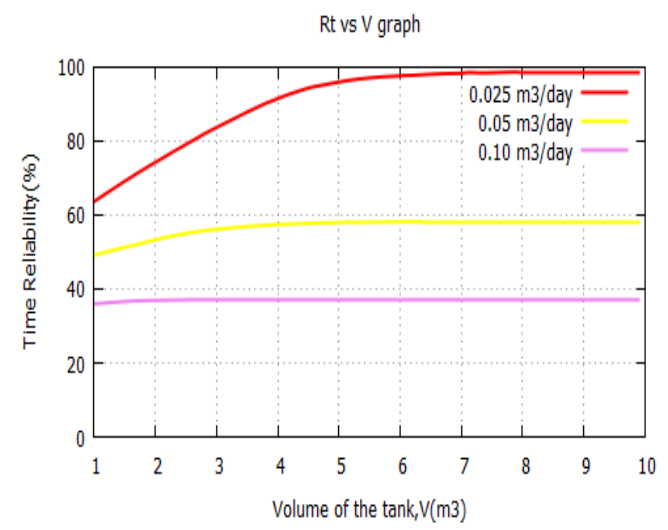

Fig. 11. Time reliability of Rajshahi for a constant catchment area of 9.29 $\operatorname{sqm}(100 \mathrm{sft})$.

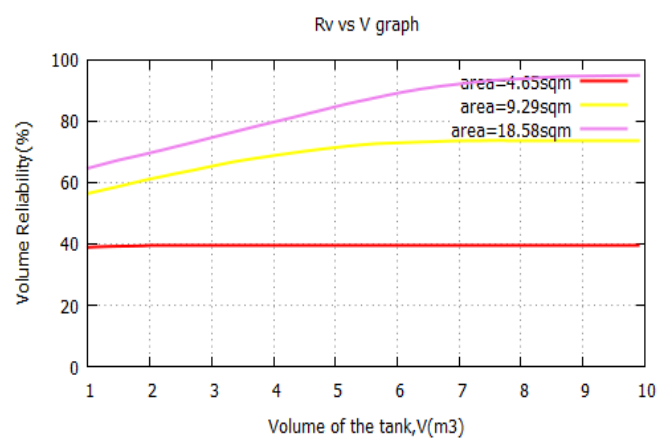

Fig. 12. Volumetric reliability of Comilla for a constant demand of a 10 member family.

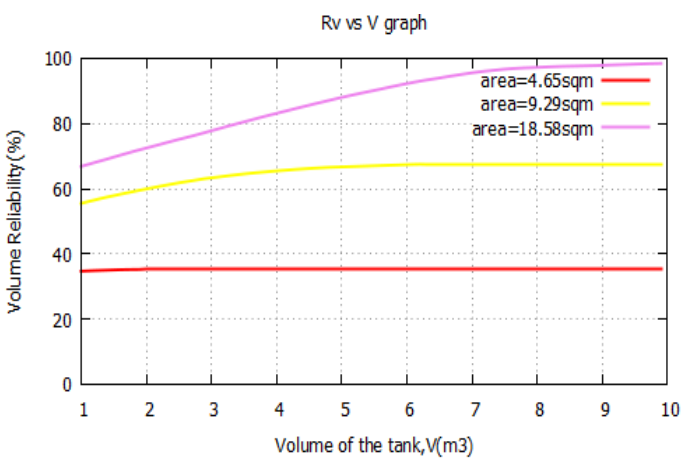

Fig. 13. Volumetric reliability of Khulna for a constant demand of a 10 member family.

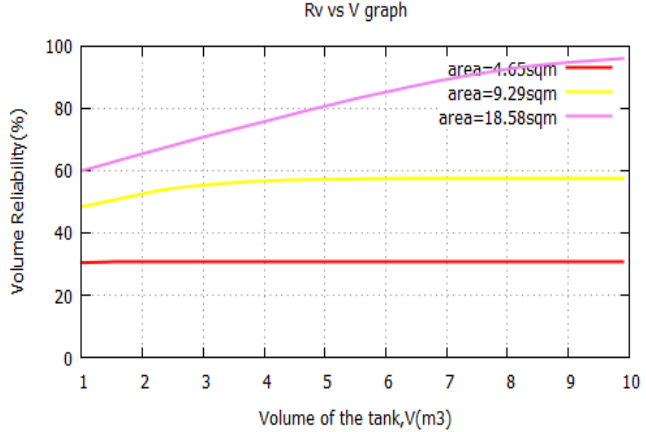

Fig. 14. Volumetric reliability of Rajshahi for a constant demand of a 10 member family.

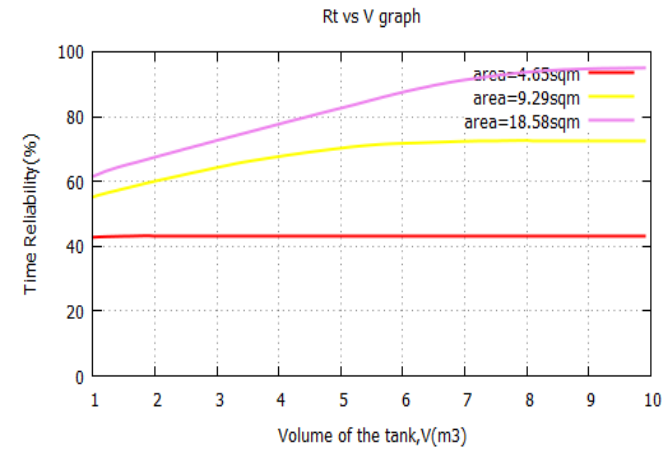

Fig. 15. Time reliability of Comilla for a constant demand of a 10 member family.

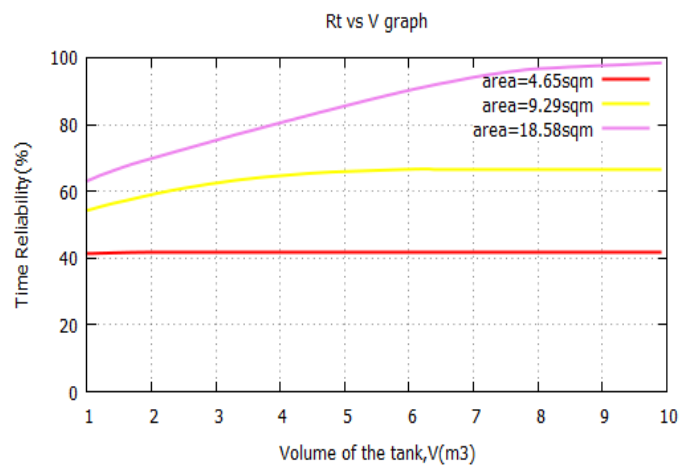

Fig. 16. Time reliability of Khulna for a constant demand of a 10 member family.

\section{Reliability Analysis}

The developed software has been used to develop reliability graphs/charts for the convenience of the user. Using the reliability graphs/charts, the user will be able to choose a tank size that will supply water according to their affordability, and desired water use. Table II shows a summary of results showing tank size, functional period and volumetric and time reliability for different catchment areas and water demand in Khulna, Rajshahi and Comilla.

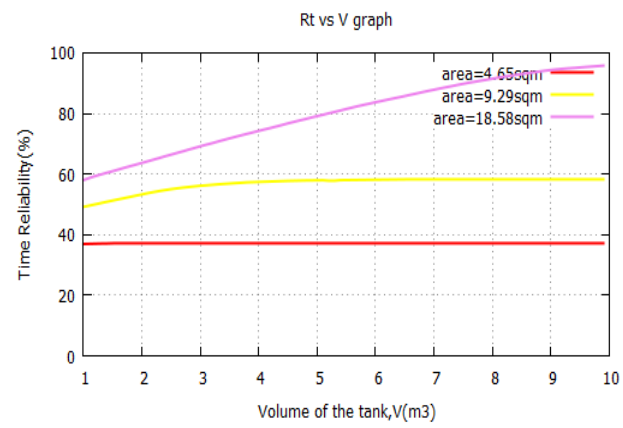

Fig. 17. Time reliability of Rajshahi for a constant demand of a 10 member family. 


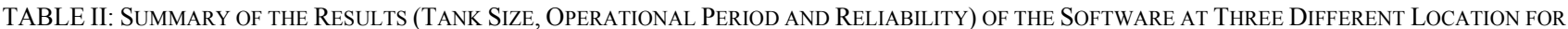
DiFFERENT CATCHMENT AREAS (DAILY WATER DEMAND $=0.05 \mathrm{M}^{3} /$ DAY; RUNOFF COEFFICIENT $=0.7$ )

\begin{tabular}{|c|c|c|c|c|c|}
\hline Location & $\begin{array}{c}\text { Catchment Area } \\
(\mathrm{sqm})\end{array}$ & Tank size $\left(\mathrm{m}^{3}\right)$ & $\begin{array}{l}\text { Functional } \\
\text { Period }\end{array}$ & Volumetric Reliability (\%) & Time Reliability (\%) \\
\hline \multirow{3}{*}{ Khulna } & 4.65 & 2.00 & July -November & 35.35 & 41.74 \\
\hline & 9.29 & 6.40 & June-January & 67.61 & 66.70 \\
\hline & 18.58 & 9.90 & February-January & 98.54 & 98.39 \\
\hline \multirow{3}{*}{ Rajshahi } & 4.65 & 1.60 & August-November & 30.64 & 37.08 \\
\hline & 9.29 & 6.60 & July- January & 57.57 & 58.23 \\
\hline & 18.58 & 9.90 & February-January & 96.06 & 95.76 \\
\hline \multirow{3}{*}{ Comilla } & 4.65 & 2.10 & July -November & 39.39 & 43.24 \\
\hline & 9.29 & 7.90 & June-January & 73.78 & 72.62 \\
\hline & 18.58 & 9.90 & February-January & 94.95 & 94.99 \\
\hline
\end{tabular}

\section{CONCLUSION AND RECOMMENDATIONS}

Rainwater harvesting is an important water supply option in salinity affected coastal areas, as well in areas suffering from ground and surface water contamination in Bangladesh. The storage tank is the most expensive and critical component of a RWHS; it also dictates the volume and time reliability of a RWHS. Since catchment (i.e., roof) area and rainfall intensity vary widely, it is difficult to estimate the optimum tank size for a RWHS in a particular area and estimate its reliability. A software/tool has been developed for estimation of optimum tank size and to assess its reliability for any area, based on rainfall pattern, catchment size and characteristics and water demand. The software was applied for three different regions of the country (Khulna, Rajshahi, and Comilla). The tank size and time/volumetric reliability of a RWHS depends on location as well as catchment area available and water demand. In Khulna and Comilla, which have similar rainfall characteristics, a rainwater harvesting system with optimum tank size would be able to provide water to a 10 -member family having a catchment area of $9.29 \mathrm{sqm}(100 \mathrm{sft})$ for eight months of a year. In Rajshahi region, a rainwater harvesting system with optimum tank size would be able to provide water for to a 10 -member family having the same catchment area (100 sft) for six months, during monsoon (June to August) and during post monsoon (September-November). The developed software could be conveniently used for selection of optimum tank size and corresponding reliability for any region within the country using local information (rainfall pattern, catchment size and characteristics, and water demand).

\section{REFERENCES}

[1] Unicef and WHO, "Progress on sanitation and drinking water - 2015 update and MDG assessment," 2015.

[2] BGS and DPHE, "Arsenic contamination of groundwater in Bangladesh," British Geological Survey (BGS) and Department of Public Health Engineering (DPHE), 2001.

[3] BBS and Unicef, "Multiple indicator cluster survey, 2012-2013," Progotir Pahey, Bangladesh Bureau of Statics (BBS) and Unicef, 2015.

[4] S. J. D. Hug et al., "Avoiding high concentrations of arsenic, manganese and salinity in deep tubewells in Munshiganj District, Bangladesh," Applied Geochemistry, vol. 26, no. 7, pp. 1077-1085, 2011.

[5] M. A. Ali, "Arsenic contamination of groundwater in Bangladesh," International Reviews for Environmental Strategies, vol. 6, no. 2, pp. 329-360, 2006

[6] ITN-BUET, Project Completion Report: Alternative Options for Access to Safe Water in Coastal Areas, funded by UKAID and CAFOD; implemented by International Training Network Centre of
Bangladesh University of Engineering and Technology (ITN-BUET) during 2013-2015, May 2015.

[7] DPHE, National MIS for WSS in Bangladesh, Policy Support Unit (PSU), Local Government Division, Ministry of Local Government, Rural Development and Cooperatives, Government of Bangladesh, 2012.

[8] M. M. Islam et al., "Feasibility and acceptability study of rainwater use to the acute water shortage areas in Dhaka city, Bangladesh," Springer, May 2010

[9] J. Mechell, Rainwater Harvesting: Soil Storage and Infiltration Systems, 2005.

[10] E. Ghisi, D. L. Bressan, and M. Martini, "Rainwater tank capacity and potential for potable water saving by using rainwater in the residential sector of south eastern Brazil," Build. Environ., vol. 42, pp. 1654-1666, 2007.

[11] Y. Zhang et al., "Alternative water resources for rural residential development in Western Australia," Water Resour. Manag., vol. 24, no. 1, pp. 25-36, January 2004.

[11] A. Fewkes and D. Butler, "Simulating the performance of rainwater collection system using behavioural models," Build. Serv. Eng. Res. Technol., vol. 21, 99-106, 2000.

[12] S. C. Chu et al., "The assessment of agricultural rainwater catchment systems in mudstone area," in Proc. the 9th International Conference on Rainwater Catchment Cistern Systems, Petorlina, Brazil, pp. 20-22, July 1999.

[13] C.-H. Liaw and Y.-L. Tsai, "Optimum storage volume of rooftop rain water harvesting systems for domestic use," JAWRA Journal of the American Water Resources Association, vol. 40, no. 3, pp. 901-912, August 2004.

[14] P. M. Ndomba and F. J. Wambura, "Reliability of rainwater harvesting systems in suburbs. A case study of Changanyikeni in Dares Salaam, Tanzania," Nile Basin Water Science \& Engineering Journal, vol. 3, issue 3, January 2010.

[15] C.-H. Liaw and Y.-L. Tsai, "Optimum storage volume of rooftop rain water harvesting systems for domestic use," JAWRA Journal of the American Water Resources Association, vol. 40, no. 3, pp. 901-912, August 2004.

[16] A. Fewkes and D. Butler, "Optimum storage volume of rooftop rain water harvesting systems for domestic use," JAWRA Journal of the American Water Resources Association, vol. 40, no. 3, pp. 901-912, August 2004.

[17] P. Dharmabalan, "High water bills: Can rain water supplement part or whole of it?" presented at 4th International Conference on Rain Water Cistern Systems, Manila, Philipines, August, 1989.

Sadia Tamanna Khan completed her B.Sc degree in civil engineering from Bangladesh University of Engineering and Technology (BUET), Dhaka, Bangladesh in 2016. Her major was in environmental engineering.

Ashef Ainan Baksh completed his B.Sc. degree in civil engineering from Bangladesh University of Engineering and Technology (BUET), Dhaka, Bangladesh in 2016. . His major was in environmental engineering.

Md Tarikul Islam Papon completed his B.Sc. degree in computer science \& engineering from Bangladesh University of Engineering and Technology (BUET), Dhaka, Bangladesh in 2015. He has been working as a faculty member in the Department of Computer Science \& Engineering at BUET as a lecturer since 2015 . 


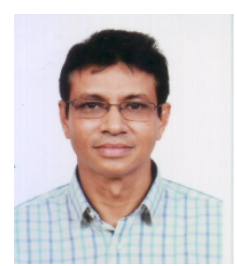

Muhammad Ashraf Ali was born in Kushtia, Bangladesh in 1965. He completed his B.Sc. degree in civil engineering from Bangladesh University of Engineering and Technology (BUET), Dhaka, Bangladesh in 1988. He then completed his M.Sc. and Ph.D. in civil and environmental engineering from Carnegie Mellon University, Pittsburgh, Pennsylvania, USA in 1991, and 1994, respectively.

He has been working as a faculty member in the Department of Civil Engineering at BUET since 1995. He is currently working as a Professor in the Department. He has over 100 publications, including 47 publications in reputed journals, including Science, Nature Geoscience, and ES\&T. His three important publications are: (1) Neumann, RB., Pracht, LE., Polizzotto, ML., Badruzzaman, ABM., and Ali, M. A., 2014. Sealing rice field boundaries in Bangladesh: a pilot study demonstrating reductions in water use, arsenic loading to field soils, and methane emissions from irrigation water. Environmental Science Technology 48 (16), 9632-9640. (2) Saha, G. C. and Ali, M. A., 2010. Arsenic Concentrations in Irrigation Water, Soil and Selected Vegetables in Bangladesh, paper accepted for publication in Int. J. of Environmental Engineering, Vol. 2(4), pp. 383-400. (3) Harvey, C.F., Swartz, C.H, Badruzzaman, A. B. M., Keon-Blute, N., Yu, W., Ali, M. A., Jay, J., Beckie, R., Niedan, V., Brabander, D., Oates, P., Ashfaque, K. N., Islam, S., Hemond, H. F., and, Ahmed, M. F., 2002. Arsenic Mobility and Groundwater Extraction in Bangladesh, SCIENCE, Vol. 298, Issue 5598, pp 1602 - 1606, 2002. His research interests include water chemistry, water quality and treatment.

Professor Ali is a Life Fellow of the Institution of Engineers, Bangladesh (IEB). He is currently serving as the Director of International Training Network (ITN) Center of BUET. 